\title{
Best practice guideline: writing a business case for service development in pathology
}

\author{
M J Galloway
}

J Clin Pathol 2004;57:337-343. doi: 10.1136/jcp.2003.012518

This guideline reviews the introduction and development of business planning in the National Health Service. A guideline for writing a business case for service development that would form part of a pathology business plan has been developed. This guideline outlines six steps that are required in the preparation of a business case. The format of the guideline has been developed largely from other national guidelines that have been published for the development of capital projects. In view of the publication of these guidelines, the scope of this guideline excludes business cases for information, management, and technology projects and large capital projects.

\section{Correspondence to: \\ DrM J Galloway, Consultant Haematologist, Department of Haematology, E Floor, Sunderland Royal Hospital, Kayll Road, Sunderland SR4 TTP, UK; mike.galloway@ chs.northy.nhs.uk}

Accepted for publication 25 September 2003
$\mathrm{T}$ his guideline reviews the introduction and development of business planning in the National Health Service (NHS). Guidelines for writing a business case for service development that would form part of a pathology business plan have been developed. Where national guidelines have been published for the preparation of business cases for capital projects and for information, management, and technology (IM\&T) projects, these are included in the literature review. However, these national guidelines are not appropriate for business cases for service development and are more appropriate for large projects that require an assessment of the involvement of the private sector through the private finance initiative. Therefore, developments including IM\&T and large capital projects are not included in this guideline.

\section{LITERATURE SEARCH}

The following search strategy was developed in the preparation of this guideline. Medline and EMBASE from 1966 to March 2003 and the Consortium of University Research Libraries catalogue (www.copac.ac.uk) were searched for the terms business planning, business plan, business case, NHS, and pathology. Relevant health circulars were searched for on the Department of Health's internet site (www.doh. gov.uk), the Department of Health's circular library (COIN) and publication library, both accessed through www.doh.gov.uk/publications/ index.html, and the UK official publications internet site (www.ukop.co.uk). Other databases searched included the National Electronic Library for Health (www.nelh.nhs.uk) and the British Library (www.bl.uk)

\section{DEFINITIONS: BUSINESS PLANNING AND BUSINESS CASE}

All NHS trusts (England and Wales), Health and Social Services trusts (Northern Ireland), and operating divisions of NHS boards (Scotland) are required to prepare annual plans. This plan (the business or service plan) is a document that sets the organisation's short and longterm plans. ${ }^{1}$ Its aim is to establish the organisation's priorities as determined by national and local policies. This document is prepared on an annual basis and usually covers three forward years. The plan includes a statement on what the organisation intends to achieve, an assessment of the level of activity against the ability of commissioners (that is, primary care trusts or equivalent purchasing organisations) to support this level of activity over the period. It also includes plans for capital development and the funding arrangements for these developments, other changes that it intends to make, and an analysis to take into account different assumptions, especially to deal with unexpected developments. Directorate business plans contribute to the development of the organisation's business plan. On an annual basis, each directorate outlines the financial and other resources that it requires to deliver its service, what is expected by the commissioners (previously known as purchasers) and senior managers in their organisation, the services to be provided, and proposals for service and capital developments. A business case is the document that supports the proposals for a new service development or a capital project. $^{2}$

"The business case should be an opportunity for clinicians who develop business cases to communicate effectively with clinical directors

Abbreviations: CPA, Clinical Pathology Accreditation; IM\&T, information, management, and technology; NHS, National Health Service; SWOT, internal strengths and weaknesses versus external opportunities and threats 
and senior managers who will decide on whether a proposal goes forward or not"

Following on from the recent changes in the structure of the NHS, together with the impact of devolution, a more unified and cooperative approach to the provision of health care services has been reintroduced. ${ }^{3}$ As a result, the term business planning has largely been replaced by the term service planning. However, the term business case is still in general use, at least in England.

\section{Why develop business plans?}

The development of business plans allows NHS organisations to integrate service developments with the financial planning year. It ensures that services are well planned, are financially viable, and that other consequences have been assessed such as staffing, maintenance, etc. It also ensures that risks have been assessed and impacts on other directorates have been taken into account. The business case document should be more than just the paperwork necessary to obtain approval of an investment. It should be an opportunity for clinicians who develop business cases to communicate effectively with clinical directors and senior managers who will decide on whether a proposal goes forward or not. It is an opportunity for the clinician to "sell" the project to decision makers in the organisation within the context of other local and national policies. In addition, the document allows clinical directors and senior managers in the organisation to evaluate the proposal objectively, and enables managers to consider alternative ways of providing a service.

\section{INTRODUCTION AND DEVELOPMENT OF BUSINESS PLANNING IN THE NHS: REVIEW OF THE LITERATURE}

The concept of business planning evolved from the introduction of the clinical directorate model of management into the NHS. ${ }^{45}$ This devolved type of clinical management was based on a model that had already been developed at Johns Hopkins Hospital in Boston, USA in the 1970s. ${ }^{6}$ In addition, as far as pathology services were concerned, at about the same time the Management Advisory Service report on staffing in pathology had recommended that the directorate model should be the basis on which pathology services were managed. ${ }^{7}$

One of the consequences of this revised structure was the need to appoint a business manager to support the work of the clinical director. ${ }^{89}$ Part of the responsibility of this new role was the requirement for clinical directorates to produce business plans that followed on from the development of a strategic plan for their directorate,$^{10}$ together with the need to prepare business cases to support service development. ${ }^{11}$ However, it was only with the introduction of NHS trusts in April 1991 that business planning became an integral part of the management process in the wider NHS. ${ }^{1}$ The methods that were developed for the business planning process evolved from the methods used in option appraisal of new services and capital equipment that had been in use before this time. ${ }^{12} 13$

Further guidance for the development of business cases was published in 1995 in the "Capital investment manual". ${ }^{2}$ The manual is a series of eight booklets including one on the preparation of business cases for capital and IM\&T projects in England and Wales. ${ }^{14}$ An equivalent document was subsequently published in Scotland. ${ }^{15}$

Subsequent guidance on the development of business cases for capital and IM\&T projects included the requirement for the NHS to explore the potential for private sector involvement through the private finance initiative. ${ }^{16}{ }^{17}$ The guidance on the development of business cases for IM\&T has recently recommended a move to the five case model. ${ }^{18}$ This model replaces the model used in the "Capital development manual". The five areas covered in this model are strategic, economic, financial, commercial, and management. Although this approach is appropriate for IM\&T projects, it would not seem to be appropriate when developing a guideline for service development in pathology.

Thus, there has been no specific guidance produced on the development of business cases for service development. Therefore, the guidelines outlined here have been developed based on the methods previously used in option appraisal and adapting the guidance produced in the "Capital investment manual".

\section{WRITING A BUSINESS CASE FOR SERVICE DEVELOPMENT IN PATHOLOGY}

\section{Getting started}

Ideas for new service development or equipment replacement can arise from several sources. Within pathology, one of the most common reasons for developing a business case is as a response to increasing workload or a need to introduce new tests into the service. Recent examples of this would be the introduction of troponin testing for myocardial ischaemia and an increased workload for consultant histopathologists in response to the setting up of new out patient services, such as endoscopy. The ideas for service developments often come from individual clinicians, but may also arise from service reviews that have been carried out by the organisation or an external review. National guidelines may also have an impact on new service developments; however, once the need for a new service or equipment replacement has been identified, the first step is an informal discussion with colleagues. Discussion with the clinical director and business manager is an important initial step to assess the likelihood of success of the proposal. Other staff to talk to at this stage would include those managers involved at the organisational level in either service or business development or planning, who will be

\section{The business case is more likely to be successful if:}

- It is a statutory/national requirement, which must be implemented; for example, Clinical Pathology Accreditation (UK) Ltd, National Service Framework, NICE guidelines, etc

- The development is part of an existing strategy

- It requires relatively simple management action with few capital or revenue consequences

- It has support in clinical directorates outside pathology

- It has a positive impact on waiting times and waiting lists

The business case is more likely to be unsuccessful if:

- It is insufficiently thought through

- It contradicts other local and national policies

- It is not physically viable

- It is not economically viable

- It is associated with unacceptably high risk

- It is not supported by the clinical director/business manager

Figure 1 Factors affecting whether a business case is successful (adapted from Ryder ${ }^{19}$ ). NICE, National Institute for Clinical Excellence. 
aware of current and new sources of funding. Discussion with the clinical director will also help to identify criteria that will be used by managers in the initial screening of business plans after submission. These criteria will vary between NHS organisations and typical criteria are summarised in fig $1 .{ }^{19}$

"One of the most common reasons for developing a business case is as a response to increasing workload or a need to introduce new tests into the service"

The team that will develop the business case will need to be established. This will usually include as a minimum senior medical, scientific, and biomedical scientific staff, together with the financial accountant attached to pathology. Other appropriate staff should also be included-for example, nurse specialists, staff from estates and supplies, and clinicians from other clinical directorates.

Many NHS organisations will have a financial threshold below which directorates will be expected to fund the developments themselves. This threshold can vary from $£ 5000$ to $£ 30000$, so it is important to be aware of each organisation's policy before beginning the business case.

Step 1: set the business case within the framework of national and local priorities (the strategic context)

The development of a business case requires three questions to be answered, namely: where are we now, where do we want to be, and how do we get there? Step 1 in the process involves answering the first two of these questions. The process is summarised in fig 2 .

Each business case will be set in the context of the overall strategy of the trust or NHS organisation involved. It is clearly important to be aware of the relevant annual plan to ensure that the proposed business case fits in with this strategy. Each NHS organisation's annual plan has to fit within the context of the overall strategy of the NHS. The strategy of the NHS will derive from several sources, which are summarised in fig 3.

The NHS plan was published in July 2000 and outlined a 10 year plan of investment and reform in the NHS. ${ }^{20}$ Equivalent documents were published in the other countries in the UK ("Our national health in Scotland", 21 "Improving health in Wales", ${ }^{22}$ and "Investing for health in Northern Ireland" ${ }^{\prime 23}$ The priorities that were outlined in these plans are implemented in part through the "Priorities and planning framework", which is published by the Department of Health and covers the period 2003-2006. ${ }^{24}$ The other countries in the UK have equivalent documents. The priorities for the next three years are summarised in fig 4. In the "Priorities and planning framework" it is stressed that these are the national priorities and therefore there will be less scope for new initiatives. This is an important point because business plans that try to identify priorities outside these areas will have a limited chance of being successful.

- Consider local and national policies that might impact on service provision

- Describe the current service

- Undertake a SWOT analysis of the service

- Identify the need for change based on the differences between the existing service and future needs

Figure 2 Step 1 of developing a business case. SWOT, internal strengths and weaknesses versus external opportunities and threats.

NHS plan (England)
Our national health (Scotland)
Improving health (Wales)
Investing in health (Northern Ireland)
Priorities and planning framework, Department of Health
National service frameworks
National Institute for Clinical Excellence (England and Wales)
NHS Quality Improvement (Scotland)
Northern Ireland Health and Personal Social Services Regulation
and Improvement Authority
Royal College of Pathologist's guidelines
Clinical Pathology Accreditation (UK) Ltd standards
Managed clinical networks
Pathology modernisation (England)
Local health plans

Figure 3 National and local policies that might influence service development in pathology.

\begin{abstract}
"Recommendations made by CPA (UK) Ltd, following an inspection of the laboratory, will usually have a high priority for implementation within a NHS organisation"
\end{abstract}

National service frameworks are also another important area that determines policy. These have now been published for mental health, coronary heart disease, cancer, older people, diabetes, and children's services, and have been adopted in each of the four countries. Other general national policies that will influence local priorities include publications from the National Institute for Clinical Excellence in England and Wales, NHS Quality Improvement in Scotland, and the Northern Ireland Health and Personal Social Services Regulation and Improvement Authority. Guidelines produced by the Royal College of Pathologists on areas such as staffing levels for consultants, in addition to the reporting of results from tests and specimens in histopathology, will also have an impact on local priorities. There is an increasing requirement for pathology laboratories in the UK to be accredited by Clinical Pathology Accreditation (UK) Limited (CPA (UK)

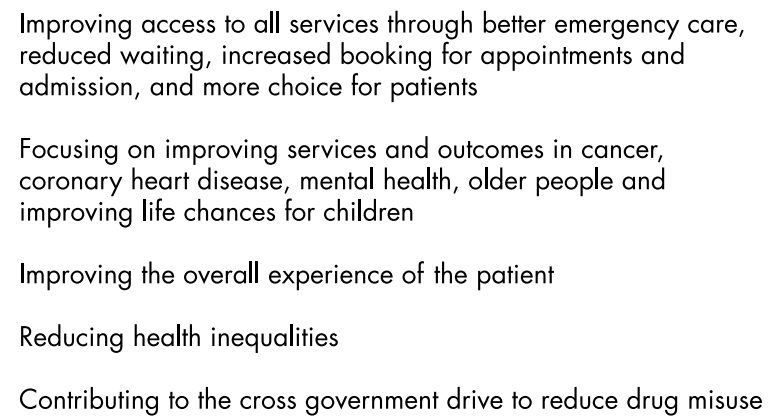

Figure 4 UK national priorities for 2003-2006. 
Ltd) to continue to provide routine clinical services. As a result, recommendations made by CPA (UK) Ltd, following an inspection of the laboratory, will usually have a high priority for implementation within an NHS organisation. It is clearly important for NHS pathology laboratories to keep up to date with the standards published by CPA (UK) $\mathrm{Ltd}^{25}$

At a regional and local level, the development of managed clinical networks, ${ }^{26}$ including the "Pathology modernisation programme in England", ${ }^{27}$ is another factor in influencing how service developments may occur in pathology. All of these national and regional priorities will be taken into account when local health care plans are developed. For each of the countries in the UK, the annual planning cycle has now been changed into a three year cycle, reflecting the changes in the way that the NHS is funded. In England, this is termed the local delivery plan, and it covers a whole strategic health authority, but is based on the plans of each primary care trust. ${ }^{24}$ In Wales, each local health board's plan is based on a health, social care, and wellbeing strategy, which will form the basis of commissioning from April 2004. ${ }^{28}$ In Scotland, each NHS board with its operating divisions, together with the local health care cooperative, is responsible for developing the local health plan. $^{29}$

The information collected from the analysis of national and local strategies will help in the next step of the process. This involves describing the aspect of the service that is under review. This will be helped by SWOT analysis in which internal strengths and weaknesses of the service are assessed against external opportunities and threats. A guide on to how to perform a SWOT analysis is given in the "Capital investment manual". ${ }^{2}$ These can be summarised in a structured format using a TOWS matrix. ${ }^{30} 31$ The TOWS matrix is a $2 \times 2$ chart in which there is analysis of strengths versus opportunities, strengths versus threats, weaknesses versus opportunities, and weaknesses versus threats. The advantage of this approach is that, although gaps in the service can clearly be highlighted, the TOWS matrix also gives the opportunity for the development of proposals that can solve some of these problems, and this work can be taken forward to step 3 as described below.

Therefore, this analysis identifies the need for change based on the differences between the existing service and the future needs, which will have resulted from the SWOT analysis. Information that will be useful at this stage is any relevant performance indicators (for example, turnaround times) or results of benchmarks comparing the service under review with a comparative service (for example, National Pathology Alliance benchmarking review). In addition, compliance or lack of compliance with the standards produced by CPA (UK) Ltd, which would help to quantify any deficiencies in the current service, are important data to collect at this stage.

\section{Step 2: define the aims and objectives}

The overall aims of the service will have previously been developed in the pathology directorate annual plan. The next step is the development of objectives for the business case that will provide a basis for formulating options for the appraisal, developing the benefit criteria against which the options would be measured, and providing criteria to judge the success of any investment. The objectives will be used to measure any improvement compared with the baseline-that is, the current service.

The objectives for the business case should relate to the outcomes that are sought from any proposal. The objectives should be SMART (specific, measurable, achievable, relevant, and with a timed element). Good objectives use words such as improve, reduce, and maintain, and they specify quantified targets. ${ }^{2}$ Examples of pathology service objectives include:

- To reduce reagent costs by $20 \%$ in 12 months.

- To reduce waiting time in a haematology clinic for patients who require a full blood count to be performed to under 20 minutes for $95 \%$ of patients within six months.

- To reduce turnaround time for biopsy results to less than 24 hours for $80 \%$ of cases of " $\mathrm{X}$ " in nine months.

Objectives such as to improve the quality of the pathology service are not good objectives because they do not identify the standard that the service must achieve or describe time scales for achievement. Objectives should be sufficiently detailed for the broad service aims to be clear, but not so specific or narrow that they preclude consideration of a range of options. Once the objectives have been developed, the aim is to produce a list of about five objectives. These can then be ranked in order of importance.

The next step is to identify benefit criteria, which can fall into one of three categories: (a) benefits that can be measured in non-financial terms, (b) benefits that can be measured financially, and (c) those benefits that cannot be easily measured. Benefit criteria can be usefully grouped into several subheadings, including: clinical quality; improved patient outcomes; staffing, such as recruitment and retention; skill mix; clerical quality, such as reduction in paperwork and therefore a reduction in transcription errors; ease of implementation; and communication. Although some of the benefits can be measured financially, cost savings should not be treated as a benefit because this will be included in the cost analysis of each of the options. An example of a benefit that is not easily measured would be the reduction in pressure on staff after the introduction of a new analyser linked to a tracking and robotic sample handling system. However, other benefits associated with a new analyser might produce benefits that are easier to measure. For example, if the analyser is capable of undertaking a wider range of tests, this may lead to measurable savings resulting from a reduction in the work referred to other laboratories.

\section{"Objectives should be sufficiently detailed for the broad service aims to be clear, but not so specific or narrow that they preclude consideration of a range of options"}

There may be constraints, which might limit the number of options that are generated. Constraints could include financial, technological compatibility with other pieces of equipment, limitations of the building in which equipment is to be installed, or difficulty in recruitment as a result of a national shortage of staff. These should be identified at this stage, although it is important to emphasise that constraints should not be too rigidly applied because they may prevent the development of creative options during the option appraisal.

\section{Step 3: develop an option appraisal}

This step is the start of answering the third question: how do we get there?

The purpose of this step is to identify as wide a range as possible of options available to meet the objectives defined in step 2. A basis for comparison of any new proposal will be required, and this is referred to as the "do nothing" or "do minimum" option. It is essential to include the do nothing option in the shortlist because it clarifies the problems with the existing service that should have been identified in step 1 . For example, if it is considered necessary that an item of equipment should be replaced, the following questions will have been addressed. How much has been spent on repairs, 
what are the difficulties in getting spare parts, what is the down time, and is the equipment functionally or technologically obsolescent, and therefore unable to produce a timely, clinically relevant result? The development of options usually involves two steps; identifying possible options on the long list and then drawing up a short list.

\section{The long list}

This is an important part of option appraisal and often involves a brainstorming session, where several different ways of achieving the objectives can be considered. For example, if one of the options is to replace a piece of laboratory equipment, other non-capital solutions should also be included, such as buying in the service from elsewhere, using non-capital options such as leasing or reagent rental. Each of the options listed under the long list should be briefly described in a short paragraph so that the full list of options that has been considered has been documented. Similarly, if there is a requirement to increase staffing, there may also be several ways of achieving the objective-for example, a change in skill mix in the existing staffing may produce options that had not previously been considered. Alternative options also include the use of increased automation, which may result in either an overall reduction in staffing requirements or the opportunity to redeploy staff to other priority areas, such as quality management. Another example is a business case that relates to the introduction of a new test. Again, other options should be developed in the long list, such as developing a combined service with a local laboratory as part of a pathology modernisation programme.

The short list

The long list should then be cut down to a manageable number of options. Some options may be eliminated because they fail the constraints identified in step 2. There may also be options that are similar-for example, the option appraisal could address the question of which technology to acquire and, once that has been answered, a second best buy appraisal can then be addressed to determine the choice of manufacturer from within the chosen technology. ${ }^{13}$ It should also be possible to screen out options that are clearly going to be unaffordable or produce inferior benefits compared with other options.

\section{Describing the short listed options}

Each of the short listed options should be described in sufficient detail for the benefits and costs to be understood and assessed in step 4. Therefore, each option should include the factors identified in fig 5. The aims should have a minimum of three options on the shortlist, including a do nothing or do minimum option.

Intended outcomes
Expected workload and throughput
Staffing consequences
Implications for the estates e.g. modification to buildings
Impact on performance indicators
Impact on financial performances
Impact on laboratory IT system e.g. interface requirements

Figure 5 Information required to describe each option on the shortlist.

\section{Step 4: assess each option for benefits and costs}

The next step is to measure the benefits and costs of the options short listed in step 3 using the benefit criteria identified in step 2 .

\section{Measuring the benefits}

For most projects involving service development in pathology it is acceptable to rank the options in order of preference according to how each option meets the objectives. For larger and more complex projects, however, it is recommended that a weighted benefit score should be developed, so that each option can be assessed against the weighted benefits. A method for developing a weighting and scoring system of benefits has been described in the "Capital investment manual". ${ }^{2}$ Briefly, a group who will undertake this analysis needs to be established. This will include members of the business case project team, together with other interested parties, such as users of pathology services and some independent participants who could help to ensure that decisions are as objective as possible and are not biased by any particular solution. Separating the exercises of weighting the benefit criteria and scoring the options also enhances objectivity.

\section{"For larger and more complex projects, however, it is recommended that a weighted benefit score should be developed, so that each option can be assessed against the weighted benefits"}

The first step is to weight the benefit criteria. These can first be given a relative rank and the most important criterion in the rank weighted at 100. Each of the other criteria should then be examined against the most important criteria and given an appropriate weighting; thus, if the first criterion is assigned a weight of 100, and the second criterion is considered to be half as important, then a weight of 50 is assigned to the second criterion. These steps are then repeated for the other criteria. The weights of each criterion are then scaled to total 100 .

The scoring of options against the benefit criteria Each of the options is then considered in turn against the benefit criteria, and each option is then scored-for example, between 0 and 100 on each of the criteria. By multiplying the weighted benefit criteria by the score a total can be derived for each option. It should then be possible to rank options in terms of benefits and to identify a preferred option on the basis of benefits only. It is important to recognise that the assigned weights of the scores given to options are value judgements. To develop the assigned weights and scores, negotiation within the group that is carrying out this work will lead to compromises being made, and it is the number of people involved in the process and their expertise that gives credibility to these value judgements.

\section{Identifying and measuring the costs}

The aim of this step of the business case is to identify the total net costs of each option. This requires an estimate to be made of the capital costs, revenue costs, costs related to any change in working practices of the organisation (such as training costs), and other one off costs (such as interface costs). It is important to be as accurate as possible when identifying costs. Any overestimate of costs may result in the business case being considered as financially not viable, whereas an underestimate will store up problems for later, and may ruin the credibility of both the project and the clinician responsible for the business case. Therefore, it is important to involve a financial manager at an early stage in the development of the case. When equipment or capital is 
involved a discounted cash flow will need to be developed for each option. ${ }^{2}$ There are several different types of costs that will need to be considered, depending on the type of service development that is under review, and these are beyond the scope of this guideline, but are covered in other publications. ${ }^{14} 1532$ It is essential that the financial accountant who is attached to the pathology service is included at this stage.

Assessing sensitivity to risk

As described above, if a weighted scoring system of benefit criteria has been used, certain assumptions and compromises will have been made. Therefore, there may be some uncertainty regarding the impact that these compromises have made on the final ranking. It is possible to assess the impact of these assumptions by altering the weighted benefits for each of the criteria. However, for most pathology service developments this will not be necessary because a simple ranking of options will have been undertaken during the option appraisal.

\section{Step 5: identify the preferred option (the proposal)}

This is a short step. It consists of analysing the information that has been generated in the preceding steps. It may be possible to identify a clearly superior option based on maximum benefits with the lowest costs. It will also be necessary to review several other aspects of the business case, and these are shown in fig 6. First, a simple table can be prepared of the relevant costs and benefits of each of the short listed options and the reasons why the preferred option has been chosen should be identified. Second, any risks associated with the preferred option should be identified and how these will be managed. For example, there may be difficulty in recruiting a new consultant post and plans that have been put in place to minimise this risk should be identified. Similarly, if a new piece of equipment is being purchased, there may be a risk regarding transfer of the service from the old equipment to the new equipment, and this should also be identified, together with how it should be managed. Finally, senior managers in the organisation will want to be reassured that there will be no negative impact on other aspects of the organisation's services-for example, no negative impact on waiting times for patients to be seen. They will also want to know whether the new service development will generate new sources of referrals, which may also adversely affect waiting times. The impact on service costs will also need to be identified. Pathologists may complain when service developments occur in other directorates and the consequences on pathology have not been included in business cases. Therefore, pathologists should ensure that the impact of any service development that they propose has been taken into account by other clinical directorates and has been discussed with them before the business case is submitted for consideration.

\section{Step 6: presenting the business case as a written report}

The final part of the development of a business case is to present the business case as a succinct written report. This report is a summary of the steps that have been undertaken

Review of relative costs and benefits of short listed options

Summarise the risks associated with the preferred option and how these will be managed

Assess the impact of the proposal

Figure 6 Identifying the preferred option: the proposal.
Introduction
Aim
Option appraisal
Proposal
Assessment of the impact of the proposal
Risk analysis
Conclusions and recommendations

Figure 7 Format for the business case document.

to develop the business case. The content and structure of the business case should be as outlined in fig 7 . The following sections need to be included.

\section{Introduction}

In the introduction the proposal should be set in the context of local and national policies. Any service problems and unmet needs that the business case will address should be summarised in this section.

\section{Aim}

This should be a clear, concise statement of the purpose of the business case.

\section{Option appraisal}

This section should summarise the options considered in the short list. A brief summary of each option should be described.

\section{Proposal}

This should be the main section of the business plan and a description of the proposal should be summarised, together with why it is superior to other options and why other options are inferior. A summary of the cost benefit analysis of the proposal should be given. An indication of how the proposal fits in with the strategic direction of the pathology directorate, organisation, and national policy should also be given. A summary of the resources required should be included in this section. These will have been derived from the costing exercise that will have been undertaken during the option appraisal, and will include staffing, revenue, and non-revenue costs, such as capital, etc. Some indication should be given of the support from other directorates, general practitioners, and commissioners. Although any savings resulting from the business case will have been taken into account in the cost benefit analysis, it is worth highlighting them at this stage.

Assessment of the impact of the proposal

A summary of any internal impact on pathology should be given, such as staffing, skill mix, building work required, interfacing, etc. In addition, a summary of any external impact outside pathology on the organisation should also be given, such as change in referral patterns, waiting times, or turnaround times.

\section{Risk analysis}

In this section, a summary of what can go wrong with the business case should be given, together with some indication of how likely this will be and what could be the impact. A description of how this would be managed and what contingencies would be put in place should be given. 


\section{Conclusion and recommendations}

The final section is to summarise the business case and indicate the recommendations that should be made to the executive team.

\section{What happens next?}

The business plan will be submitted to the pathology directorate and will be considered against other bids. These would then go forward to be assessed by the executive team and, based upon the relevant criteria, each of the business cases will be prioritised. As discussed above, guidance has already been given as to how to identify these criteria in advance of preparing the business case. The executive team will either agree to proceed with the business case, agree in principle but request further work and resubmission, agree to proceed conditional on funding from the commissioners, or turn down the proposal completely and recommend it should proceed no further. Clearly, this last outcome is the worst case. However, the aim of this guideline is to prevent this happening. Many business cases will receive a high priority but will not be funded in the year they are submitted. This is not necessarily the end of the process. Many will then go forward in the next financial year for review and may well have moved up the priority list. In addition, there is often funding made available part way through the financial year, and high priority business cases that were not initially funded may well still attract funding. However, if there has been a delay in approving a business case the costs may have to be reviewed, particularly if quotes for any tenders were time limited.

\section{"Many business cases will receive a high priority but will not be funded in the year they are submitted"}

In the current environment, the scope for developing business cases outside of local or national policies is limited. However, that should not stop business cases that do not appear to be immediately part of a local or national priority from being developed. Appropriate discussion with managers in either service development or planning may identify a way of targeting a business case to an appropriate source of funding.

In conclusion, business planning and the development of a successful business case in pathology present a challenge to all those working in that service. Time needs to be taken to prepare well, collect accurate information, and gain support from colleagues for any plan to be successful.

\section{ACKNOWLEDGEMENTS}

I am most grateful to Mr I Tarbit, Executive Director of Strategy and Business Development, City Hospitals Sunderland NHS Trust for his help in developing this guideline. The steps involved in developing a business case have been derived from the internal guidance developed at City Hospitals Sunderland NHS Trust. I am also grateful to the following who have commented on drafts of this article: Dr A Galloway, Dr C A Bloxham, and Dr W S A Smellie.

\section{REFERENCES}

1 NHS Management Executive. NHS trusts: a working guide. London: HMSO, 1990.

2 NHS Executive. Capital investment manual. Business case guide. London: HMSO, 1994.

3 Galloway M. The evolving structure of the NHS in the United Kingdom. ACP News Summer 2003:26-9.

4 Scott T. Clinical directorates: background. In: Galloway M, ed. Clinical director of pathology. Oxford: Radcliffe Medical Press, 1999:1-10.

5 Chantler C. Management reform in a London hospital. In: Carle N, ed. Managing for health result. London: King Edward's Hospital Fund for London, 1990.

6 Heyssel RM, Gainter JR, Kues IW, et al. Decentralized management in a teaching hospital. N Engl I Med 1984;2:1477-80.

7 Management Advisory Service to the NHS. Review of pathology services staffing. A report to the manpower planning advisory group. London: MAS, 1987.

8 Penny H, Walker DA. Managing in a clinical directorate: geriatrics and general medicine. In: Burrows M, Dyson R, Jackson P, et al, eds. Management for hospital doctors. Oxford: Butterworth Heinmann, 1994:285-8.

9 Meecham J. Managing in a clinical directorate: medicine. In: Burrows $M$, Dyson R, Jackson P, et al, eds. Management for hospital doctors. Oxford: Butterworth Heinmann, 1994:286-92.

10 Galloway M, Thompson R. On a business path. Health Serv J 1990;100:672.

11 Stuart J, Hicks JM. Good laboratory management: an Anglo-American perspective. J Clin Pathol 1991;44:793-7.

12 HN (87) 18. Option appraisal. A guide for the National Health Service. London: Department of Health and Social Security, 1987.

13 Option appraisal medical and scientific equipment. A guide for the National Health Service. London: Department of Health and Social Security.

14 NHS Executive. Capital investment manual. London: HMSO, 1994.

15 Management Executive. Scottish capital investment manual. Edinburgh: NHS Scotland, 1996.

16 HSG (95) 15. Private finance and capital investment projects. Leeds: NHS Executive, 1995.

17 HSG (95) 48. Information management and technology (IM\&T). Procurement and private finance. Leeds: NHS Executive, 1995.

18 Department of Health. IM\&T business case guidance-the five case model. London: Department of Health, 2002 (www.doh.gov.uk/pfi/imt.htm).

19 Ryder S. Actions arising as a result of a SWOT analysis. In: York Health Economics Consortium. Business planning for providers of health care services. Essex: Longman Group UK Limited, 1993:43-53.

20 Secretary of State for Health. The NHS plan. London: HMSO, 2000.

21 Minister for Health and Community Care. Our national health. Edinburgh: NHS Scotland, 2000.

22 Minister for Health and Social Services. Improving health in Wales. Cardiff: The National Assembly for Wales, 2001.

23 Minister for Health, Social Services and Patient Safety. Investing for health. Belfast: DHSSPS, 2002

24 Crisp, N. Improvement, expansion and reform: the next 3 years. Priorities and planning framework 2003-2006. London: Department of Health, 2002.

25 Standards for the Medical Laboratory. Sheffield: Clinical Pathology Accreditation (UK) Ltd, 2003.

26 MEL (1999) 10. Introduction of managed clinical networks within the NHS in Scotland. Edinburgh: Scottish Executive, 1999.

27 HSC 1999/170. Modernisation of pathology services. London: NHS Executive, 2000.

28 Welsh Assembly Government. Planning and commissioning NHS services. Cardiff: Welsh Assembly Government.

29 Minister for Health and Community Care. Partnership for care. Scotland's Health White Paper. Edinburgh: NHS Scotland, 2003.

30 Weihrich $\mathbf{H}$. The TOWS matrix, a tool for situational analysis. Long Range Planning 1982;15:54-66.

31 Galloway M, Bloxham C, Wansborough R. An evaluation of six marketing methods applied to an NHS pathology laboratory. 2. Developing a strategy. Clinician in Management 1995;4:9-11.

32 Hartell S, Purchasing equipment, In: Galloway M, ed. Clinical director of pathology. Oxford: Radcliffe Medical Press, 1999:125-38. 